06

\title{
Микротвердость армко-железа с разной исходной структурой после прокатки в среде гелия или азота
}

\author{
() О.В. Клявин, Н.Н. Аруев, Л.И. Деркаченко, Ю.М. Чернов, В.В. Шпейзман \\ Физико-технический институт им. А.Ф. Иофрфе РАН, \\ 194021 Санкт-Петербург, Россия \\ e-mail: klyavin@mail.ioffe.ru; shpeizm.v@mail.ioffe.ru
}

(Поступило в Редакцию 11 мая 2017 г.)

\begin{abstract}
Исследованы зависимости микротвердости $(H)$ от нагрузки $(P)$ поверхностных слоев образцов армкожелеза с различной исходной структурой: отожженных и после равноканального углового прессования (РКУП). Микротвердость измерялась на воздухе после прокатки образцов в среде гелия или азота. Обнаружено различное влияние указанных сред на зависимости $H(P)$ для предварительно отожженных образцов по сравнению с подвергнутыми РКУП. Оно связано с различием их исходной дефектной структуры и характером сил связи атомов гелия и молекул азота с дислокациями, определяющими интенсивность их проникновения в поверхностный слой исследованных образцов. Получены кривые выделения гелия из образцов, прокатанных в различных средах, и измерено его количество.
\end{abstract}

DOI: 10.21883/JTF.2017.11.45143.2328

Исследования физических закономерностей явления механодинамической диффузии (МХД) показали, что интенсивность МХД частиц внешней среды (воздуха, азота, гелия, воды) в процессе деформации кристаллических материалов зависит от типа их кристаллической и дефектной структуры и происходит по зарождающимся и движущимся в них дислокациям [1-6]. Явление МХД имеет атермическую природу и эффективно работает даже в среде жидкого гелия и азота [7-9]. Изучение физического механизма явления МХД частиц внешней среды в различных типах твердых тел в процессе пластической деформации показало, что оно зависит от ряда физико-химических параметров, определяющих интенсивность этого процесса [2-5]. К ним относятся: тип частиц среды, ее плотность и состояние (газовая, жидкая), характер исходной дефектной структуры и степень пластической деформации исследуемых материалов. Проникновение частиц внешней среды в тонкий поверхностный слой материала может приводить к облегчению или затруднению движения дислокаций в нем и тем самым влиять на его структуру и механические свойства. Этот процесс сопровождается изменением микротвердости поверхностного слоя материалов на глубине динамического проникновения в них частиц среды [9]. Задача настоящей работы заключалась в изучении влияния газообразных сред азота и гелия при прокатке на микротвердость образцов железа с различной исходной дефектной структурой: отожженных и после равноканального углового прессования (РКУП). Образцы диаметром 5 и высотой $10 \mathrm{~mm}$ прокатывались ступенями по изменению толщины от 0.5 в начале до $0.1 \mathrm{~mm}$ в конце прокатки в среде азота или гелия до толщины $0.4 \mathrm{~mm}$. После прокатки в указанных средах на приборе ПМТ-3 измерялась микротвердость $(H)$ по Виккерсу в зависимости от нагрузки $(P)$ в диапазоне $P=2-50 \mathrm{~g}$ для средней части полученных тонких лент.
Ошибка однократного измерения величины $H$ составляла $\pm 5 \%$. При анализе результатов использовалось среднее значение, определенное по десяти однотипным измерениям. Измерялась также микротвердость образцов до прокатки в зависимости от нагрузки. Определение содержания гелия в прокатанных образцах проводилось высокоразрешающим масс-спектрометрическим методом с порогом чувствительности по $\mathrm{He}^{4}-10^{9}$ атомов [10]. С помощью этого и других масс-спектрометрических методов было показано, что глубина проникновения гелия в деформируемые металлы может достигать $\sim 8 \mu \mathrm{m}[8]$. Кривые экстракции гелия из образцов были получены при постоянной скорости их нагрева $\left(5^{\circ} \mathrm{C} / \mathrm{min}\right)$ в области температур $T=20-1200^{\circ} \mathrm{C}$.

На рис. 1 приведены зависимости микротвердости от нагрузки $H(P)$ для отожженных и РКУП образцов же-

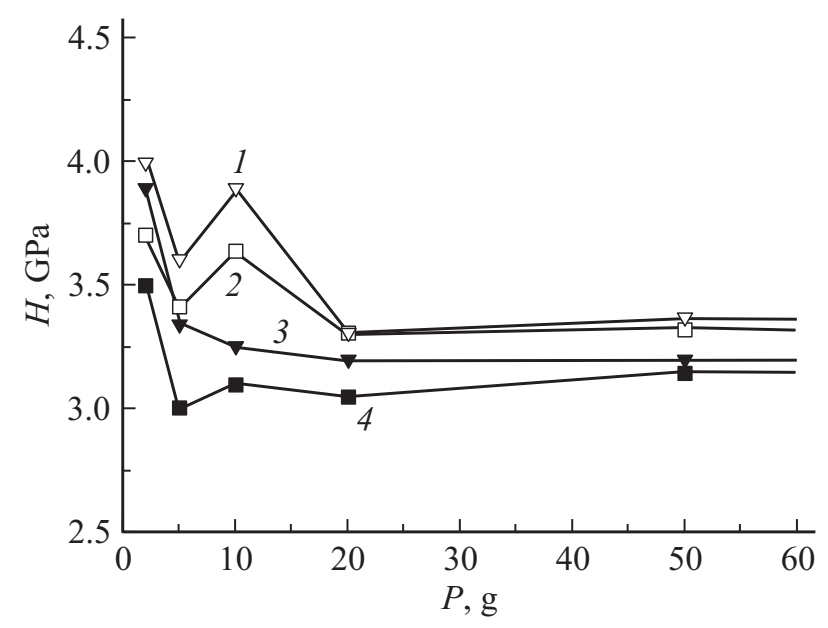

Рис. 1. Зависимости микротвердости от нагрузки для образцов мелко- $(1,2)$ и крупнокристаллического $(3,4)$ армко-железа, прокатанных в среде гелия $(1,4)$ и азота $(2,3)$. 
леза, прокатанных в среде азота и гелия (кривые $1-4)$. Обнаружено изменение этих зависимостей при переходе от среды азота к среде гелия при малых нагрузках $(P=2-20 \mathrm{~g})$. Оно связано с различной интенсивностью химического взаимодействия среды азота и гелия с поверхностным слоем образцов в процессе их индентирования. При прокатке образцов на каждом ее этапе возникает динамически возбужденный ювенильный слой Дебая-Хюккеля [4]. Он способствует динамическому захвату частиц внешней среды движущимися дислокациями, их более интенсивному размножению и влияет на величину $H$. Для РКУП образцов кривая $H(P)$ для среды гелия идет несколько выше, чем для азота (ср. кривые 1 и 2 на рис. 1). При $P>20 \mathrm{~g}$ величина $H$ остается примерно постоянной для обоих типов сред. Атомы гелия и молекулы азота, несмотря на некоторое колебание микротвердости в указанном диапазоне нагрузок, упрочняют тонкий поверхностный слой образцов в процессе их прокатки, причем для среды гелия этот эффект заметно больший. Это связано с тем, что молекулы азота захватываются движущимися дислокациями и двигаются в них при меньшей энергии связи с ядром дислокации по сравнению с атомами гелия [6]. Влияние сил изображения и торможения дислокаций примесями внешней среды, проникшими в поверхностный слой образцов за счет механизма МХД, рассмотрено в [11]. Атомы гелия при взаимодействии с ядрами движущихся дислокаций в ОЦК решетке тормозят их движение в поверхностном слое образцов [4]. Они переходят из одного междоузлия решетки в соседнее, вытесняя собственный атом в междоузлие, и упрочняют поверхностный слой образцов. Увлечение примесного атома гелия движущимися дислокациями происходит лишь в динамическом режиме при наличии локального импульса, обеспечивающего инерционное динамическое преодоление барьера: захват атома гелия перегибом на дислокации и перенос его в поверхностный слой образца. В [3] показано, что этот процесс более вероятен, чем отрыв перегиба от примесного атома. Молекулы азота проникают в материал по ядру движущейся краевой дислокации как солитоны Френкеля-Конторовой [12]. Это облегчает их захват и увлечение движущимися дислокациями и приводит к более низкому упрочнению поверхностного слоя по сравнению с упрочнением, вызванным атомами гелия (ср. начальные участки кривых 1,2 на рис. 1).

Из рис. 1 видно, что разница между микротвердостью после прокатки в среде азота и гелия для образцов мелкокристаллического (после РКУП) и отожженного (крупнозернистого) железа невелика и в области нагрузок до $20 \mathrm{~g}$ (глубины отпечатка $\sim 1.5 \mu \mathrm{m}$ ) имеет разный знак: в первом случае, как отмечалось выше, среда гелия приводит к несколько большему упрочнению поверхностного слоя, чем среда азота, во втором - это соотношение обратное (кривые 3, 4 на рис. 1). Прокатка крупнозернистых образцов приводит к массовому образованию новых дефектов и тем самым способствует зарождению новых потенциальных ловушек как для

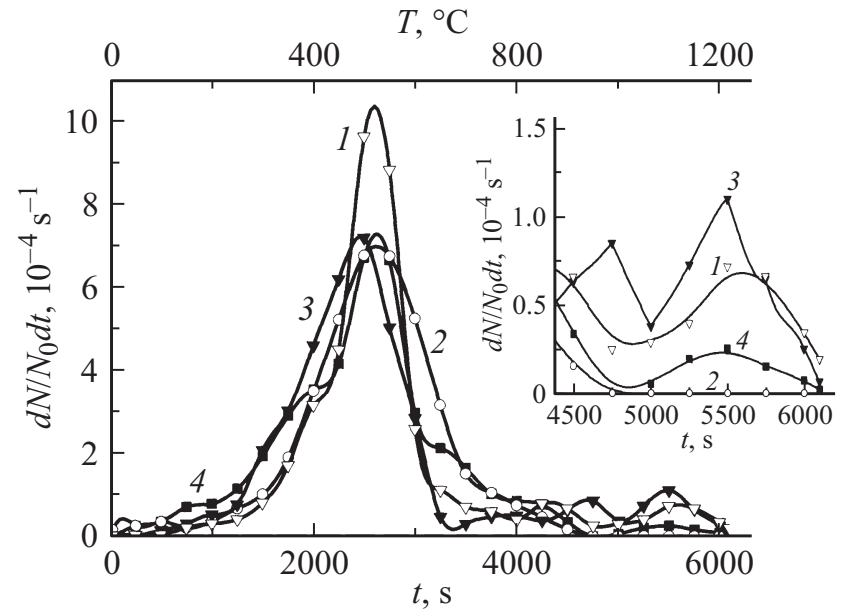

Рис. 2. Зависимости скорости изменения доли выделившегося гелия из образцов мелко- $(1,2)$ и крупнокристаллического $(3,4)$ армко-железа, прокатанных в среде гелия $(1,3)$, азота (2) и воздуха (4). На врезке показан высокотемпературный участок зависимости.

атомов гелия, так и для молекул азота, проникающих в поверхностный слой материала по механизму МХД. Для мелкокристаллических образцов, получивших интенсивную пластическую деформацию по методу РКУП, последующая прокатка, очевидно, скажется на количестве и виде ловушек атомов и молекул среды не столь сильно. Поскольку азот проникает в деформируемые образцы более интенсивно, чем гелий [13], то можно предположить, что его большое количество в поверхностном слое ответственно за увеличение микротвердости при малых нагрузках исходно-крупнозернистых образцов, прокатанных в азоте, по сравнению с прокатанными в гелии.

Следует заметить, что объемная микротвердость исследованных материалов до прокатки различалась более чем в 2 раза. После прокатки эта разница сократилась до $\sim 10 \%$, причем микротвердость РКУП образцов слегка уменьшилась, а отожженных резко возросла. Если упрочнение отожженных образцов при прокатке является очевидным, то аномальное поведение образцов, полученных интенсивной пластической деформацией, при последующей деформации (разупрочнение), как и аномальное упрочнение при отжиге, также возможно и наблюдалось, например, в работах $[14,15]$.

На рис. 2 приведены кривые выделения гелия из образцов РКУП-железа, прокатанных в гелии и азоте (кривые 1,2), и то же для исходно-отожженных образцов, прокатанных в гелии и на воздухе (кривые 3,4), в координатах: скорость выделения, нормированная на общее количество выделившегося гелия, - время (температура). Количество гелия для образцов, прокатанных в среде гелия, существенно превосходило его количество для образцов, прокатанных в других средах, источником которого в них мог быть так называемый „воздушный“, или „реликтовый“ гелий, в том числе и адсорбированный 
поверхностью образца. В образцах, прокатанных в гелии, его количество было 6 и $4.5 \cdot 10^{12} \mathrm{at} / \mathrm{cm}^{2}$ соответственно для крупно- и мелкозернистого железа и более чем на порядок меньше в остальных образцах. Температура основного максимума выделения гелия для всех образцов практически совпадает $\left(T \sim 550^{\circ} \mathrm{C}\right)$, но их ширина и высота разные. Это приводит к различному выделению гелия в области высоких и низких температур и означает, что атомы гелия находятся как в однотипных, так и в различных типах ловушек в зависимости от исходной структуры и среды прокатки. Воздушный гелий начинает выделяться уже вблизи комнатной температуры. Выделение гелия наблюдается вплоть до максимальной температуры $T \approx 1230^{\circ} \mathrm{C}$. При $T>900^{\circ} \mathrm{C}$ возникает ряд максимумов, ответственных за наличие глубоких ловушек гелия, освобождение гелия из которых возможно лишь при высоких температурах. Особенно это характерно для мелкозернистой структуры (см. врезку на рис. 2). Таким образом, типы ловушек гелия и характер его выделения после прокатки образцов железа в различных средах отличаются и зависят от их исходной дефектной структуры и вида последующей деформации. ${ }^{1}$

Результаты настоящей работы показывают, что среда азота и гелия оказывает различное влияние на величину микротвердости поверхностных слоев образцов мелкои крупнокристаллического железа, прокатанных в указанных средах. Оно обусловлено различным характером их исходной дефектной структуры и сил связи атомов гелия и молекул азота с дислокациями. Это влияет на интенсивность проникновения по механизму МХД исследованных сред в поверхностный слой образцов в процессе их прокатки и способствует изменению микротвердости в области малых нагрузок.

\section{Список литературы}

[1] Klyavin O.V., Likhodedov N.P., Orlov A.N. // Progr. Surf. Sci. 1990. Vol. 33. N 4. P. 259-383.

[2] Клявин О.В. // ФТТ. 1993. Т. 5. Вып. 3. С. 513-541.

[3] Орлов А.Н. // ФТТ. 1987. Т. 29. Вып. 12. С. 3676-3678.

[4] Бакенов А.С., Кирсанов В.В., Клявин О.В., Лиходедов Н.П., Орлов А.Н. // ФТТ. 1988. Т. 30. Вып. 8. C. $2459-2463$.

[5] Клявин О.В., Мамырин Б.А., Хабарин Л.В., Чернов Ю.М. // ФТТ. 2005. Т. 47. Вып. 5. С. 837-842.

[6] Калашников Е.В., Клявин О.В., Титаренко И.Г. // ЖТФ. 2013. Т. 83. Вып. 4. С. 81-84.

[7] Клявин О.В., Николаев В.И., Смирнов Б.И., Хабарин Л.В., Чернов Ю.М., Шиейзман В.В. // ФТТ. 2007. Т. 49. Вып. 9. C. $1590-1594$.

[8] Клявин О.В., Николаев В.И., Поздняков О.Ф., Смирнов Б.И., Чернов Ю.М., Шпейзман В.В. // ФТТ. 2010. Т. 52. Вып. 9. С. $1758-1762$.

[9] Клявин О.В., Аруев Н.Н., Деркаченко Л.И., Федоров В.Ю., Чернов Ю.М, Шпейзман В.В. / В сб. материалов XXII Петербургские чтения по проблемам прочности. 2016. C. $82-85$.

\footnotetext{
1 Энергетические характеристики различных типов ловушек гелия для каждой из сред требуют дополнительного исследования.
}

[10] Клявин О.В., Мамырин Б.А., Хабарин Л.В., Чернов Ю.М., Юденич В.С. // ФТТ. 1976. Т. 18. С. 1281-1287.

[11] Владимиров В.И., Клявин О.В., Кусов А.А. // ФТТ. 1985. Т. 27. Вып. 10. С. 3171-3174.

[12] Конторова Т.А., Френкель Я.И. // ЖЭТФ. 1938. Т. 8. Вып. 1. С. 89-93.

[13] Клявин О.В., Николаев В.И., Поздняков О.Ф., Смирнов Б.И., Чернов Ю.М., Шиейзман В.В. // ФТТ. 2010. Т. 52. Вып. 12. С. 2336-2340.

[14] Xuang X, Hansen N. // N. Tsuji. Science. 2006. V. 312. P. 249-251.

[15] Мавлютов А.М., Латынина Т.А., Мурашкин М.Ю., Валиев Р.3., Орлова Т.С. // ФТТ. 2017. Т. 59. Вып. 9 (в печати). 